\title{
Effect of Punica Granatum (Pomegranate) on serum ALT and AST in Carbon tetrachloride induced liver damage in Wistar Albino Rats
}

\author{
Halima Sadia ${ }^{1}$, Qazi Shamima Akter ${ }^{2}$, Rukhsana Afroz ${ }^{3}$, Tashfia Siddiqua ${ }^{4}$
}

\begin{abstract}
Background: Liver diseases are associated with significant morbidity and mortality. Punica granatum may have free radical scavenging activity and it can be used for the prevention and treatment of liver damage. Objective: To observe the hepatoprotective effects of Punica granatum on $\mathrm{CCl}_{4}$ induced liver damage in rats. Methods: The experimental study was carried out in the Dept of Physiology, Dhaka Medical Ccollege, Dhaka from July 2013 to June 2014. For this purpose, 36 wistar albino rats were studied. After acclimatization for 7 days, they were divided into two groups-control and experimental group. Control group were subdivided into $\mathrm{BC}$ (Baseline control), $\mathrm{CC}\left(\mathrm{CCl}_{4}\right.$ treated control) and SC (Silymarin treated control). Experimental group were subdivided into CP-APT $\left(\mathrm{CCl}_{4}\right.$ pretreated and aqueous extract of pomegranate treated), $\mathrm{CP}$-EPT $\left(\mathrm{CCl}_{4}\right.$ pretreated and ethanolic extract of pomegranate treated) and APP-CT (Aqueous extract of pomegranate pretreated and $\mathrm{CCl}_{4}$ treated). Each sub group consisted of 6 rats. All rats received basal diet for 8 days. In addition to basal diet on $8^{\text {th }}$ day, $\mathrm{BC}$ received single dose olive oil and $\mathrm{CC}$ received $\mathrm{CCl}_{4}$. Rats of $\mathrm{SC}$ received silymarin for 8 consecutive days In experimental groups, CP-APT received aqueous extract of Pomegranate and CP-EPT received ethanolic extract of Pomegranate for 8 consecutive days. Moreover, APP-CT received aqueous extract of Pomegranate for 8 consecutive days and $\mathrm{CCl}_{4}$ only on $8^{\text {th }}$ day. All rats were sacrificed on $9^{\text {th }}$ day and then blood samples were collected. Serum ALT and AST levels were estimated by using standard laboratory kits. Statistical analysis was done one way ANOVA and Bonferroni test. Results: The mean serum AST and ALT levels were significantly $(\mathrm{p}<0.001)$ higher in CC in comparison to those of BC. Serum AST and ALT levels of all experimental groups were significantly $(\mathrm{P}<0.001)$ lower than $\mathrm{CC}$. Silymarin used as a standard reference also exhibited significant hepatoprotective activity against $\mathrm{CCl}_{4}$ induced hepatotoxicity Conclusion: From the result of present study it can be concluded that, Pomegranate may have hepatoprotective effect by lowering ALT and AST levels.
\end{abstract}

Keyword: Pomegranate, $\mathrm{CCl}_{4}$, Rats. ALT, AST

J Bangladesh Soc Physiol. 2016, June; 11(1): 23-28 For Authors Affiliation, see end of text.

http://www.banglajol.info/index.php/JBSP

\section{Introduction}

he liver is the largest metabolizing organ in the body which regulates homeostasis of the different body system ${ }^{1}$. Recent

Received 3rd Feb. 2016; Accepted 13th May 2016 surveillance studies in the United States documented an annual incidence of newly diagnosed chronic liver disease of 72.3 per 100,000 populations. Over half $(57 \%)$ of patients have hepatitis $\mathrm{C}$ viral infection, followed by

J Bangladesh Soc Physiol. 2016, June; 11(1): 23-28 
alcohol induced liver disease (24\%), non alcoholic fatty liver disease (9\%), and hepatitis $B$ viral infection (4\%). Liver disease accounts for over 44,000 deaths per year in the United States (1.9\% of all deaths), placing it as the eight leading cause of death ${ }^{2}$.

The principal causative factors for the liver diseases in developing countries are environmental toxins, parasitic disease, hepatitis $\mathrm{B}$ and $\mathrm{C}$ viruses, and hepatotoxic drugs and hepatotoxic agents (carbon tetrachloride ,thiocetamide $)^{3}$. Carbon tetrachloride $\left(\mathrm{CCl}_{4}\right)$ is an industrial chemical that does not occur naturally. It can cause pathological lesions in treated animals that closely resemble the symptoms of cirrhosis in human, and so it is considered an excellent model to evaluate the efficacy of hepatoprotectants. $\mathrm{CCl}_{4}$ induced hepatotoxicity depends on dose and duration of exposure $4,5,6$.

Pomegranate Linn. (Punicaceae), commonly known as pomegranate, recently described as nature's power fruit ${ }^{7}$. Pomegranate fruits are globally consumed as fresh fruit and in processed forms like juice, jam, wine, oil and also in extract supplements ${ }^{8}$. It is a rich source of polyphenolic compounds that include flavonoids and hydrolyzable tannins ${ }^{9}$. Pomegranate has been known to posses considerable pharmacological properties as pomegranate peel is a rich source of antioxidants, especially polyphenols. In some recent studies, pomegranate fruit and flower extracts exhibited free-radicals scavenging properties with simultaneous potent hepatoprotection against chemically induced liver damage in rodents ${ }^{10,11}$.

Silymarin is a standardized extract of the milk thistle (Silybum marianum) which is used as a standard drug and exhibiting potent hepatoprotective activity at the dose range from
$25-200 \mathrm{mg} / \mathrm{kg}$ in various experimental and clinical studies ${ }^{12,13}$.

Liver diseases have become a worldwide problem and are associated with significant morbidity and mortality but its medical management is currently inadequate ${ }^{14}$. Therefore, there is a growing focus to evaluate scientific basis for the traditional herbal medicines that possess hepatoprotective effects ${ }^{15}$.Very few studies has been done yet to investigate the hepatoprotective effect of pomegranate.

With the above background, the present study was carried out to observe the hepatoprotective effects of Pomegranate in experimental animals after inducing hepatotoxicity by $\mathrm{CCl}_{4}$.

\section{Methods}

This experimental study was conducted in the Department of Physiology, Dhaka Medical College, Dhaka from July 2013 to June 2014. Total 36 apparently healthy Wister albino rats, weighing between 150 to 200 grams and age ranging from 90 to 120 days, was used for this study. The rats were purchased from the animal house of Department of Pharmacy, Jahangir Nagar University, Savar, Dhaka. The protocol of this study was approved by Ethical Review Committee of Dhaka Medical College.. The rats were kept in metallic case in the animal house of Institute of Nutrition and Food Science, University of Dhaka (DU). Before conducting the study, rats were kept in a standard laboratory condition on a 12/12 hour light/dark cycle for 7 days for acclimatization. All the rats received basal diet for 21 days. Total study period was 15 consecutive days. After selection and acclimatization for 7 days, the rats were divided into two groups, control group and experimental group. Control group were subdivided into BC (base line control group, $\mathrm{n}=6$ ) and $\mathrm{CC}$ (Carbon 
tetrachloride treated control group, $n=6$ ) and SC (Silymarin treated control group, $n=6$ ). Experimental group were subdivided into CPAPT $\left(\mathrm{CCl}_{4}\right.$ pretreated and aqueous extract of pomegranate treated group, $n=6$ ), CP-EPT $\left(\mathrm{CCl}_{4}\right.$ pretreated and ethanolic extract of pomegranate treated group) and APP-CT (Aqueous extract of pomegranate pretreated and $\mathrm{CCl}_{4}$ treated group, $\mathrm{n}=6$ ). After grouping, initial body weight of all the rats were measured on $1^{\text {st }}$ day. In addition to basal diet on $8^{\text {th }}$ day, BC received single dose olive oil and $\mathrm{CC}$ received $\mathrm{CCl}_{4}$. Along with basal diet, $\mathrm{SC}$ received silymarin for 8 consecutive days 30 minutes after administration of $\mathrm{CCl}_{4}$. In experimental groups, in addition to basal diet, CP-APT received aqueous extract of Pomegranate for 8 consecutive days 30 minutes after administration of $\mathrm{CCl}_{4}$ and CP-EPT received ethanolic extract of Pomegranate for 8 consecutive days 30 minutes after administration of $\mathrm{CCl}_{4}$ along with basal diet. Moreover, APP-CT received aqueous extract of Pomegranate for 8 consecutive days and $\mathrm{CCl}_{4}$ only on $8^{\text {th }}$ day along with basal diet. $200 \mu 1$ $\mathrm{CCl}_{4}$ was diluted with $200 \mu \mathrm{l}$ of olive oil (1:1 dilution).

Pomegranate extract preparation:

Fruits of Pomegranate were washed and the peels were manually removed, cut into small pieces and then dried at room temperature for 2 days. Dried peels of Pomegranate were grinded in an electrical grinder which was subjected to drying overnight in an air-oven electrical dryer. Then the dried sample of Pomegranate was taken in the jar. After that, ethanol and water was poured into the jar in order to prepare alcoholic and aqueous extract of Pomegranate. Then, Pomegranate extract was filtered with fine cloth. By evaporating the solvent using a rotator evaporator under reduced pressure in water bath at a temperature of $60^{\circ} \mathrm{C}$. It was stored in freeze at around $4^{\circ} \mathrm{C}$ and was fed to the experimental rats.

Before sacrifice, final body weights of all the rats were measured. On $9^{\text {th }}$ day all the animals were anaesthetized with the help of $30 \%$ chloroform and then sacrificed. The blood samples (approximately $5 \mathrm{ml}$ ) were collected from the heart by directly puncturing with sterile disposable syringes and taken in separate clean and dry test tubes with proper identification numbers. Then blood was centrifuged at a rate of $4000 \mathrm{rpm}$ for 5 minutes. After that the supernatant serum was separated from the blood, collected in a labeled eppendroff and preserved in a refrigerator at $-20^{\circ} \mathrm{c}$ until analytical measurement of serum for AST and ALT in Department of Pathology, DMC. Data was reported in Mean and $\pm \mathrm{SE}$. Statistical analyses were done by One-way ANOVA and Bonferroni test as applicable.

\section{Results}

Initial body weights of all rats were almost similar and showed no statistically significant difference of these values among the groups.

The final and $\%$ change of body weight was significantly $(\mathrm{p}<0.001)$ lower in group $\mathrm{CC}$ when compared to that of group BC, SC, CP-APT and CP-EPT. (Table I).

In this study, the mean serum ALT and AST level were significantly $(\mathrm{P}<0.001)$ higher in $\mathrm{CC}$ in comparison to that of $\mathrm{BC}$ and $\mathrm{SC}$. But these levels were significantly $(\mathrm{p}<0.001)$ lower in CPAPT, CP-EPT and APP-CT in comparison to that of CC. Again there was no significant difference in those levels between CP-APT and CP-EPT (Table II). 
Table-I: Initial and final body weight and percent (\%) change of body weight in different groups of rats $(n=35)$

\begin{tabular}{lcccccc}
\hline Parameter & $\begin{array}{c}\mathrm{BC} \\
(\mathrm{n}=6)\end{array}$ & $\begin{array}{c}\mathrm{CC} \\
(\mathrm{n}=6)\end{array}$ & $\begin{array}{c}\mathrm{SC} \\
(\mathrm{n}=6)\end{array}$ & $\begin{array}{c}\text { CP_APT } \\
(\mathrm{n}=6)\end{array}$ & $\begin{array}{c}\text { CP_EPT } \\
(\mathrm{n}=6)\end{array}$ & $\begin{array}{c}\text { APP-CT } \\
(\mathrm{n}=5)\end{array}$ \\
\hline Initial body weight & $155 \pm 2.59$ & $168.33 \pm 4.79$ & $160.00 \pm 5.1$ & $170.83 \pm 5.56$ & $158.33 \pm 4.02$ & $186 \pm 6.85$ \\
Final body weight & $210.8 \pm 2.72$ & $195 \pm 5.16^{* * *}$ & $216.67 \pm 3.3$ & $216.67 \pm 4.96$ & $210 \pm 5.18$ & $221 \pm 7.44$ \\
\% change weight & $36.1 \pm 1.59$ & $15.90 \pm 1.12^{* * *}$ & $35.85 \pm 3.06$ & $27.06 \pm 1.77$ & $32.72 \pm 2.12$ & $18.9 \pm 1.17$ \\
[F-I/I×100] & & & & & & \\
\hline
\end{tabular}

Results are expressed as Mean \pm SE. One way ANOVA followed by Bonferroni test was performed to compare between groups. $\mathrm{n}=$ Number of rats. (*** $\mathrm{p}<0.001 \mathrm{CC}$ vs BC, SC, CP-APT, CP-EPT) BC: Baseline control group $\mathrm{CC}$ : $\mathrm{CCl}_{4}$ treated control group SC: Silymarin treated control group $\mathrm{CP}$ APT: $\mathrm{CCl}_{4}$ pretreated and aqueous extract of pomegranate treated group $\mathrm{CP} \_\mathrm{APT}: \mathrm{CCl}_{4}$ pretreated and alcoholic extract of pomegranate treated group APP-CT: Aqueous extract of pomegranate pretreated and $\mathrm{CCl}_{4}$ treated group

Table II: Serum alanine aminotransferase (ALT) and aspartate aminotransferase (AST) in different groups of rats $(n=35)$

\begin{tabular}{lcccccc}
\hline Parameters & $\begin{array}{c}\mathrm{BC} \\
(\mathrm{n}=6)\end{array}$ & $\begin{array}{c}\mathrm{CC} \\
(\mathrm{n}=6)\end{array}$ & $\begin{array}{c}\mathrm{SC} \\
(\mathrm{n}=6)\end{array}$ & $\begin{array}{c}\text { CP_APT } \\
(\mathrm{n}=6)\end{array}$ & $\begin{array}{c}\text { CP_EPT } \\
(\mathrm{n}=6)\end{array}$ & $\begin{array}{c}\text { APP-CT } \\
(\mathrm{n}=5)\end{array}$ \\
\hline ALT $(\mathrm{U} / \mathrm{L})$ & $36.17 \pm 1.75$ & $823.33 \pm 91.3^{\$ \$ \$}$ & $38.33 \pm 1.09$ & $37.67 \pm 1.4^{* * *}$ & $34.33 \pm 1.5^{* * *}$ & $\begin{array}{c}384 \pm 40.73^{* * *} \\
\text { AST }(\mathrm{U} / \mathrm{L})\end{array}$ \\
\hline
\end{tabular}

Results are expressed as MeanSE. Statistical analysis was done by One way ANOVA followed by Bonferroni test. $\left({ }^{\$ \$} \$ p 0.001 \mathrm{CC}\right.$ vs BC, CC vs SC) $\left({ }^{* * *} \mathrm{p}<0.001 \mathrm{CP}-\mathrm{APT}\right.$ vs CC, CP-EPT vs CC, SCvs CP-APT, CP-EPT) $\mathrm{n}=$ Number of rats. $\mathrm{BC}$ : Baseline control group $\mathrm{CC}: \mathrm{CCl}_{4}$ treated control SC: Silymarin treated control group, CP_APT: $\mathrm{CCl}_{4}$ pretreated and aqueous extract of pomegranate treated group, CP_EPT: $\mathrm{CCl}_{4}$ pretreated and alcoholic extract of pomegranate treated group APP-CT: Aqueous extract of pomegranate pretreated and $\mathrm{CCl}_{4}$ treated group ALT: Alanine transfersae,AST: Aspartate transferase.

\section{Discussion}

In the present study, the mean $\%$ change of body weight was significantly lower in $\mathrm{CC}$ in comparison to that of $\mathrm{BC}$. This finding is similar with those of some researcher ${ }^{16}$. Again this level was significantly higher in experimental groups in comparison to that of CC. These findings are in consistent with those of some other researchers ${ }^{17}$.

In this study, significantly higher serum AST and ALT levels in CC in comparison to that of BC was observed. This finding was in agreement with other researchers ${ }^{17,18}$. Again, mean serum AST and ALT levels were significantly lower in
$\mathrm{SC}$ in comparison to that of CC. This finding is similar with those of some researcher ${ }^{19}$. However, no significant difference in ALT and AST was observed by some researchers ${ }^{7}$. This discrepancy may be due to the fact that in that study different extract of pomegranate was used. It has been suggested that most remarkable pathological characteristics of $\mathrm{CCl}_{4}$ induced hepatotoxicity are fatty liver, cirrhosis and necrosis. These pathological lesions are due to formation of reactive intermediates such as trichloromethyl free radical $\left(\mathrm{CCl}_{3}\right)$ in the endoplasmic reticulum ${ }^{20}$. In the present study, hepatic damage was observed in $\mathrm{CCl}_{4}$ treated rats 
as evidenced by an elevation of serum ALT and AST levels. Again, lower levels of serum ALT and AST observed in CP-APT, CP-EPT and APP-CT rats suggest that the possibility of Pomegranate extract to give protection against $\mathrm{CCl}_{4}$ induced liver injury. Bodies of literature suggested that pomegranate has protective effect on liver damage due to its antioxidant properties. Antioxidant potential of pomegranate juice and peel, seeds extracts is attributed to their high polyphenolic content ${ }^{21,22}$. Polyphenolic content has strong free radicals scavenging and antioxidant properties ${ }^{23}$. In this study effects both extracts of pomegranate are almost same. No significant difference was found between them. So both can be used as hepatoprotective. These hepatoprotective effects of pomegranate are most likely due to free radical scavenging activity. ${ }^{22}$ However, the exact mechanism involved in the hepatoprotective activity of Pomegranate extract against $\mathrm{CCl}_{4}$ induced liver damage in rats cannot be elucidated from the present study as concentration of free radicals was not assayed.

\section{Conclusion}

From the result of the study, it may be concluded that Pomegranate may have some hepatoprotective role against $\mathrm{CCl}_{4}$ induced liver damage.

Conflict of Interest: None

\section{Acknowledgement}

Authors of this study acknowledge the Institute of Nutrition and Food Science, University of Dhaka for laboratory support.

\section{Author affiliations:}

*1. Halima Sadia, Assistant professor, Department of Physiology, BGC Trust Medical College, Chittagong.Tele: 01711160642,01882540573. E mail: hspapri@gmail.com

2. Qazi Shamima Akter, Professor and Head, Department of Physiology, Dhaka medical college, Dhaka.

3. Rukhsana Afroz, Assistant professor, Department of Physiology, Bikrampur Bhuiyan Medical College, Munshiganj, Dhaka.

4. Tashfia Siddika, Head of the Department, Department of Physiology, Mugda Medical College, Dhaka

* Corresponding author

\section{References}

1. J Biol Waugh A, Grant A. Ross and Wilson anatomy and physiology in health and illness. 9th ed. Edinburgh: Elsevier; 2001. 500p

2. Crawford JM. Robbins and Cotran Pathologic Basis of Disease. $7^{\text {th }}$ ed. New Delhi: Elsevier a devision of Reed Elseiver India Private Limited; 2004. 880p.

3. Bagban IM, Roy SP, Chaudhary A, Das SK, Gohil KJ, Bhandari KK. Hepatoprotective activity of the methanolic extract of Fagonia indica Burm in carbon tetra chloride induced hepatotoxicity in albino rats. Asian Pac J Trop Biomed 2012: 246-9.

4. Muriel P, Mourelle M. Prevention by silymarin of membrane alterations in acute $\mathrm{CCI}^{4}$ liver damage. $\mathrm{J}$ Appl Toxicol 1990; 10(4): 275-9.

5. Kim KH, Kim HC, Hwang MY, Oh HK, Lee TS, Chang YC, Song HJ, Won NH, Park KK. The antifibrotic effect of TGF-2 1 siRNAs in murine model of liver cirrhosis. Biochem Biophys Res Commun 2006; 343 (4): $1072-8$.

6. Weber LW, Boll M, Stampfl A. Hepatotoxicity and mechanism of action of haloalkanes: carbon tetrachloride as a toxicological model. Crit Rev Toxicol 2003; 33(2): 105-36.

7. Moneim AEA, Dkhil MA, Al-Quraishy S. Studies on the effect of pomegranate(Pomegranate) juice and peel on liver and kidney in adult male rats. J Med Plants Res 2011; 5(20): 5083-8.

8. Gil MI, Tomas-Barberan FA, Hess-Pierce B, Holcroft DM, Kader AA. Antioxidant activity of pomegranate juice and its relationship with phenolic composition and processing. J Agric Food Chem 2000; 48(10): 4581-9.

9. Zahin M, Aqil F, Ahmad I. Broad spectrum antimutagenic activity of antioxidant active fraction of Pomegranate L. peel extracts. Mutat Res 2010; 703(2): 99-10.

10. Celik I, Temur A, Isik I. Hepatoprotective role and antioxidant capacity of pomegranate (Pomegranate) flowers infusion against trichloroacetic acid-exposed in rats. Food Chem Toxicol 2009; 47(1): 145-9.

11. Bishayee A, Bhatia D, Thoppil RJ, Darvesh AS, Nevo E, Lansky EP. Pomegranate-mediated chemoprevention of experimental hepatocarcinogenesis involves Nrf2-regulated antioxidant mechanisms.Carcinogenesis 2011; 32(6): 888-96.

12. Ramadan LA, Roushdy HM, Abu Senna GM, Amin NE, El-Deshw OA. Radioprotective effect of silymarin 
against radiation induced hepatotoxicity. Pharmacol Res 2002; 45(6): 447-54.

13. Wills PJ, Asha VV. Protective effect of Lygodium flexuosum (L.) Sw. extract against carbon tetrachloride-induced acute liver injury in rats. $\mathrm{J}$ Ethnopharmacol 2006; 108(3): 320-6.

14. Bruck R, Hershkoviz R, Lider O, Aeed H, Zaidel L, Matas Z, Barg J, Halpern Z. Inhibition of experimentally-induced liver cirrhosis in rats by a nonpeptidic mimetic of the extracellular matrixassociated Arg-Gly-Asp epitope. J Hepatol 1996; 24(6): 731-8.

15. Dhiman A, Nanda A, Ahmad S. A recent update in research on the antihepatotoxic potential of medicinal plants. J Chin integr med 2012; 10(2): 117-27.

16. Uzma K, Kumar BS, Anees S. Red wine ameliorates $\mathrm{CCI}_{4}$ - induced acute liver injury in rats. Aust $\mathrm{J}$ Biomed Sci.AJBS. 2011; 1(1):1-7.

17. Ashoush IS, EI-Batawy OI, EI-Shourbagy GA. Antioxidant activity and hepatoprotective effect of pomegranate peel and whey powders in rats. Annals Agric Sci 2013; 58(1): 27-32.

18. Abdel-Rahman MK, El-Megeid AA. Hepatoprotective Effect of Soapworts (Saponaria officinalis), Pomegranate Peel (Punica granatum L) and Cloves
(Syzygium aromaticum linn) on mice with $\mathrm{CCI}_{4}$ hepatic intoxication. World J Chem. 2006;1(1):41-6.

19. Eshwaraiah MC, Manasa N, Kavitha K, Bardalai D. Evaluation of hepatoprotective activity of ethanolic extract of Pomegranate. Int J Pharm Pharm Sci 2013;5(4):220-3.

20. Rao MEB, Dama GY. Evaluation of hepatoprotective activity of Pomegranate leaves on carbon tetrachloride induced hepatotoxicity in rats. Int J Universal Pharm Life Sci 2011; 1(2): 23-36.

21. Agha FE, Hassannane MM, Omara EA, Hasan AM, El-Toumy SA. Protective Effect of Pomegranate peel extract against Pentachlorophenol-induced oxidative Stress, cytogenetic Toxicity and hepatic Damage in rats. Aust J Basic Appl. Sci 2013; 7(2): 853-64

22. Seeram NP, Adams LS, Henning SM, Niu Y, Zhang Y, Nair M, Heber D. In vitro antiproliferative, apoptotic and antioxidant activities of punicalagin, ellagic acid and a total pomegranate tannin extract are enhanced in combination with other polyphenols as found in pomegranate juice. J Nutr Biochem 2005; 16 (1): $1-23$.

23. Salim AB, Abou-Arab AA, Mohamed SR, Eldesouky TA . Influence of Pomegranate (Pomegranate L.) on dimethoate induced hepatotoxicity in rats. Int Veterinary Agric Food 2014 ; 8(8): 871-6. 